\title{
Cross-Cultural Adaptation and Validation of the Highly Sensitive Person Scale to the Adult Spanish Population (HSPS-S)
}

\author{
Antonio Chacón (D) \\ Manuela Pérez-Chacón (ID) \\ Mercedes Borda-Mas ${ }^{2}$ \\ María Luisa Avargues- \\ Navarro (D) ${ }^{2}$ \\ Ana María López-Jiménez ${ }^{3}$ \\ 'International School of Doctoral Studies, \\ University of Seville, Seville, 4I013, Spain; \\ ${ }^{2}$ Department of Personality, Assessment, \\ and Psychological Treatment, University \\ of Seville, Seville, 4I018, Spain; \\ ${ }^{3}$ Department of Experimental \\ Psychology, University of Seville, Seville, \\ Spain
}

Correspondence: María Luisa AvarguesNavarro

Department of Personality, Assessment, and Psychological Treatment, Faculty of

Psychology, University of Seville, C/

Camilo José Cela s/n, Seville, 41018, Spain

Tel +34954557806

Email avargues@us.es

Manuela Pérez-Chacón International School of Doctoral Studies, University of Seville, México Pavillion,

Paseo de las Delicias s/n, Seville, 4I0I3, Spain

Tel +34 672239205

Email manpercha@alum.us.es
Purpose: This article describes a cross-cultural adaptation of the Highly Sensitive Person Scale (HSPS) to the adult Spanish population, and psychometric analysis of its validation and reliability.

Methods: Convenience sampling by participant accessibility was used. The original version was adapted culturally and linguistically using the back-translation method, and a pilot study was done with 88 participants. Data processing and analysis was performed with the SPSS v.25 and LISREL v.9.2 statistical packages. The psychometric properties were studied in a sample of 8358 participants using exploratory factor analysis and confirmatory factor analysis, and examining factorial invariance and internal consistency.

Results: The results confirmed a Spanish version with 27 items in five-dimensions: sensitivity to overstimulation (SOS), aesthetic sensitivity (AES), low sensory threshold (LST), fine psychophysiological discrimination (FPD) and harm avoidance (HA). Invariance across gender of this factor structure was demonstrated and reliability indices were good.

Conclusion: These findings demonstrate that the HSPS is an appropriate tool for evaluating high sensitivity in the adult Spanish population.

Keywords: sensory processing sensitivity, sensitivity to overstimulation, aesthetic sensitivity, low sensory threshold, fine psychophysiological discrimination, harm avoidance

\section{Introduction}

Sensitivity of sensory processing (SPS) is related to the concept of sensitivity to sensory stimulation, although it involves a broader view under the theoretical framework of environmental sensitivity. ${ }^{1}$ Aron and Aron $^{2}$ defined SPS as heightened awareness of sensorial stimulation, deeper cognitive processing of environmental stimuli, more emotional and physiological reactivity and behavioral inhibition. People with this personality trait show stronger autonomic nervous system activation in stressful situations, more intense positive and negative emotional responses, and feelings toward others, strong perception of subtle differences, knowledge of long-term consequences, and low threshold of pain and low tolerance to high levels of sensory input. . $^{3,4}$

The literature does not refer to SPS related as to a mental disorder, although it was reported to have psychological consequences. Several studies have demonstrated its relationship with emotional alterations, ${ }^{5-8}$ stress, ${ }^{9}$ and other variables of personal development ${ }^{8-10}$ and wellbeing. ${ }^{7-10}$ 
Adverse childhood environments may cause a stronger negative impact on highly sensitive people, leaving them at higher risk of developing behavioral or psychopathological problems in adulthood. ${ }^{7-11}$ This vulnerability is demonstrable throughout their development, ${ }^{12}$ and affects their health. A possible explanation is that higher sensitivity increases general physiological excitation, causing chronic stress with later adverse consequences to their health ${ }^{13}$ and work. ${ }^{9-14}$ However, in adequate environments, they may show optimum development, with positive effects on health, education and professional development. $^{15}$

This stable personality trait is associated with a more sensitive central nervous system. Recent studies report that sensory hypersensitivity is a manifestation of central sensitization, an amplification of the neural signal that triggers hypersensitivity to pain, such as fibromyalgia and chronic fatigue, as well as complex diseases with multiple symptoms. ${ }^{16}$ Dixon et $\mathrm{al}^{16}$ reported that women are more sensitive, with lower thresholds and tolerances than men to some pain stimuli, possibly attributable to attention bias, ${ }^{17}$ higher perceived stress, ${ }^{13}$ and others.

The applicability of this instrument will provide us with feedback in our cultural context, which has not been available until now. The active processes of elaboration and modification of the instrument in the cross-cultural adaptation to Spanish will allow us to compare participants from other cultures and countries with Spanish-speaking participants, due to the dynamic nature of the scale. This adaptation may help these individuals flourish in Spanish society.

The 27-item Highly Sensitive Person Scale (HSPS) was developed by Aron and Aron $^{2}$ to identify people with the high sensitivity trait. The original design showed a unidimensional SPS structure. ${ }^{13-18}$ Later, studies have demonstrated possible multidimensionality of the HSPS, identifying two-, three- and four-factor structures in validations in Europe, Asia and Central America.

One of these studies in an adult population suggested a sensitivity model with two factors, low sensory threshold (LST) and ease of excitation (EOE), in 19 items. ${ }^{19}$ Montoya-Pérez et $\mathrm{a}^{20}$ found a dimension called processed sensitivity (PS,) maintaining the low sensory threshold factor in a 16 -item version. Smolewska et $\mathrm{al}^{21}$ proposed a three-factor structure comprising aesthetic sensitivity (AES), low sensory threshold (LST) and ease of excitation (EOE). These refer to aesthetic awareness of the setting, unpleasant sensory excitation and a feeling of being overwhelmed by external and internal stimuli, respectively. This structure was supported by later studies. ${ }^{22,23}$ In the four-factor solution, ${ }^{24}$ the first factor was related to overstimulation under pressure over time, called sensitivity to overstimulation (SOS). The second, called sensitivity to external stimuli (SES), represents high levels of excitation and reaction to strong stimuli. The third factor reflects affectation by aesthetics and art, called aesthetic sensitivity (AES). Finally, the fourth factor being on guard against threatening situations, is defined as harm avoidance (HA), related to the behavioral inhibition system (BIS), specifically with the tendency in SPS to adopt controlled avoidance strategies to prevent distress. ${ }^{4}$

In the literature on scales for measuring high sensitivity in adults, most of the studies share some characteristics, such as the sample size (around 1000 participants or fewer), a mostly student population (aged 18-22), except for the one by Konrad and Herzberg, ${ }^{22}$ more participation of women and shorter versions than the original. In spite of the strong social interest that high sensitivity and people with SPS have awakened in recent years, there are no validated instruments for the Spanish population. Therefore, our objectives were to adapt and validate an instrument for the adult Spanish population. Two studies were performed, one for each of the respective objectives. The objective of Study 1 was the linguistic and cultural adaptation of the original English version of the Highly Sensitive Person Scale (HSPS) developed for a North American population. ${ }^{2}$ The objective of Study 2 was to examine the psychometric properties of that Spanish version. The HSPS-S factor structure was studied to see whether it fit a unidimensional factor structure similar to the original version by Aron and Aron $^{2}$ or a structure with several factors as in later validations done in other countries as mentioned above. We also wanted to test for factorial invariance across gender.

\section{Study I \\ Objective}

Make a cross-cultural adaptation of the original version of the HSPS for the adult Spanish population (HSPS-S).

\section{Method}

The process included translation and linguistic and cultural adaptation of the HSPS questionnaire from English to Spanish. Adaptation and translation to Spanish of the HSPS was done by bilingual experts following the reverse translation methods of Beaton et $\mathrm{al}^{25}$ and Wild et $\mathrm{al}^{26}$ and 
the guidelines of the International Test Commission, ${ }^{27}$ for test translation/adaptation.

\section{Instrument}

The HSPS ${ }^{2}$ is a self-report test for identifying highly sensitive people. It consists of 27 items with seven answer choices rated on a Likert-type scale from 1 (not at all) to 7 (extremely). All the items are direct in a range of 27-189. Higher scores show more sensory sensitivity. In their original research, Aron and Aron ${ }^{2}$ found internal consistency scores of $\alpha=0.87$ and $\alpha=0.85$

\section{Procedure}

Study 1 was carried out from October 2019 through September 2020. The stages and a summary of HSPS transcultural adaptation to the Spanish population are shown in Appendix 1.

\section{Results}

Translation and Linguistic and Cultural Adaptation

A Committee of eight Experts trained in the English language and in English translation, of whom two were Health Sciences professionals, three were university professors and three were psychologists (two clinical psychologists), considered semantic and contextual equivalence between the HSPS and the HSPS-S. The 27 items on the original scale were retained in the HSPS-S. At the end of the first seven stages of the translation-back-translation process, a pilot test was administered to 88 participants.

Three yes/no answer questions were asked on comprehension (Did you have any problem understanding the questions asked?), clarity (Did you have any problem with the clarity of the questions asked?) and ambiguity (Did you find any of the questions ambiguous?) to evaluate equivalence. The answers showed that the questions had been asked clearly (92.05\%), were understood $(95.46 \%)$ and unambiguous $(94.32 \%)$.

The results of items translation were classified by how well their conceptual meaning was conserved, showing that nine items $(33 \%)$ were considered literal (linguistic back-translation and/or semantically equivalent to the question in the original version) and 18 items (67\%) were described as similar (linguistically and/or semantically equivalent, but with words with a different meaning). After the pilot study, it was unnecessary to make any changes in any of the items, since they were all understood correctly (See Appendix 1).
In conclusion, the transcultural adaptation of the original version of the HSPS to an adult Spanish population (HSPS-S) meets the highest level of linguistic, cultural and conceptual equivalence.

\section{Study 2 Objective}

To study the psychometric properties of the scale, that is, factor structure, reliability and invariance across gender of the Spanish version of the HSPS-S.

\section{Method}

Participants

The sample was from a larger study with 10,821 adults recruited in a community context by convenience sampling, for accessibility. For this study, inclusion criteria were as follows: 1) Spanish nationality and 2) minimum age of 18. The exclusion criteria were as follows: 1) participants from Spanish-speaking countries but not Spanish nationality, even though they share the same language, ${ }^{25}$ 2) all the data not filled out or the test battery not answered properly, and 3) informed consent not expressly given.

After applying these criteria, the sample in this study was a total of 8358 adults aged 18 to $70(M=33.44 ; S D=$ 11.53). The participants were from all of the autonomous regions of Spain, but mostly from Catalonia (20.11\%), Madrid (19.41\%), Andalusia (14.18\%), Valencia (8.56\%) and Galicia (6.58\%). Occupations were mostly in education (12.28\%), healthcare (9.77\%), administration/management $(8.17 \%)$, trade $(4.99 \%)$, hotel/restaurant $(3.55 \%)$ and ICT $(3.35 \%)$.

\section{Procedure}

First, the population of highly sensitive people, associations interested in the subject and professionals and staff of Spanish universities, were contacted for its diffusion. Then the tests were administered anonymously in an online application, which took 45-60 min. After reading a brief introduction with the study objectives, the participants signed their informed consent to participate under the conditions of research. Then they proceeded to the tests that were always presented in the same order. Participation was voluntary, anonymous, and no compensation of any kind was received for it. The participants could drop out of the study at any time.

The study was approved by the Doctoral Studies Program Academic Committee of the Escuela 
Internacional de Doctorado de la Universidad de Sevilla [International Doctoral School of the University of Seville] (EIDUS). Appropriate measures were taken to safeguard the information in compliance with Organic Law 3/2018 on data protection and guarantee of digital rights. The study was performed following the code of ethics of the World Medical Association (Helsinki Declaration, 2013), the Código Deontológico del Psicólogo [Psychologist's Code of Ethics] (Colegio Oficial de Psicólogos, 1987) and the recommended ethical principles for research with human participants. ${ }^{28}$

\section{Data Analysis}

HSPS-S data processing and analysis was done using the SPSSv.25 and LISRELv.9.2 statistical packages. Exploratory factor analysis (EFA) and confirmatory factor analysis (CFA) were calculated. Significance was accepted at $5 \%$ throughout.

Descriptive analyses of the sample were performed using the mean and standard deviation as quantitative variables, and absolute and relative frequency of the categorical variables. The underlying HSPS dimensions were determined by cross validation. The sample was divided into two halves at random for internal structure validity. Exploratory factor analysis was performed with the first half (Subsample 1) and confirmatory factor analysis with the second half (Subsample 2). For the EFA, sample adequacy was measured using the Kaiser-Meyer-Olkin test $(\mathrm{KMO})^{29}$ and Bartlett's sphericity. ${ }^{30}$ Exploratory factor analysis (EFA) of principal components (PCA) was conducted with PROMAX rotation. After the EFA, confirmatory factor analysis was estimated with Subsample 2, using Diagonally Weighted Least Squares (DWLS). The following indices were calculated to evaluate CFA fit: NonNormed Fit Index (NNFI) and Comparative Fit Index (CFI). Values $>0.90$ were interpreted as indicators of acceptable fit. ${ }^{31}$ A root mean square error of approximation (RMSEA) $<0.08$ indicates adequate fit. ${ }^{32}$ Pearson's correlation coefficient was used for the scores of the items and the dimensions of the HSPS-S. Multi-group CFA was performed with LISREL to test HSPS-S measurement invariance across gender. Invariance exists if the $\Delta$ in the CFI and RMSEA are low (usually accepted as $\Delta<$ $0.01) .{ }^{33}$

The Cronbach's alpha and McDonald's ordinal omega were used to estimate the overall reliability of the HSPS and the factors found. Internal consistency was considered acceptable at $>0.80$.
The Student's $t$-test was used to examine the differences in means between men and women on the total HSPS-S and its factors. The Cohen's coefficient was used to evaluate the effect size. Reference values $<0.30$, $0.30-0.50$ and $>0.50$ were taken as low, medium and large sizes, respectively. ${ }^{34}$

\section{Results \\ Descriptive Analysis of HSPS-S Items}

Table 1 shows the means and standard deviations of the 27 items and the HSPS-S average. All of the items had adequate variability $(S D \geq 0.89)$. Skewness and kurtosis (absolute values centered at 0 ) varied from 0.54 to 2.32 and from 0.06 to 6.68 , respectively. These results show that the main trend and variability of absolute values of the items on the scale were adequate, and therefore item distribution was not severely vulnerable to the normality assumption, as most of them were below 2 for skewness and 7 for kurtosis. ${ }^{35}$

\section{Construct Validity}

\section{Exploratory Factor Analysis of the HSPS-S}

EFA was estimated with Subsample 1 ( $\mathrm{n}=4091$ participants) of the 27 HSPS-S items. The results of the KaiserMeyer-Olkin test $(\mathrm{KMO}=0.94)$ and the Bartlett's sphericity test $\left(\chi^{2}(351)=43771.65 ; \mathrm{p}<0.001\right)$ were adequate. The EFA one-, three-, four- and five-factor structures were tested to determine the best fit to the data. The five-factor solution, according to the Kaiser criterion (eigenvalues over 1) explained $53.73 \%$ of the variance (see Table 2).

Table 3 shows the five-factor factor solution found. Factor I, related to the feeling of being overwhelmed by internal and external demands, explained the highest percentage of variance $(33.76 \%)$. Its nine items reflect sensitivity to overstimulation (SOS) $(5,11,14,16,19,21,23,26$ and 27). Factor II, aesthetic sensitivity (AES), includes six items related to aesthetic awareness of the environment $(2,3,8$, 10, 15 and 22). Factor III groups items related to sensory distress from overstimulation in five items covering the low sensory threshold (LST) dimension (1, 7, 9, 18 and 25). These three factors correspond to the ease of excitation (EOE), aesthetic sensitivity (AES) and low sensory threshold (LST) factors in the Smolewska et $\mathrm{al}^{21}$ and Grimen and Diseth $^{23}$ models. Factor IV refers to discrimination of subtilties or physical/physiological sensitivity in reaction to internal stimuli (pain, fear, effects of caffeine or hunger). This dimension, called fine psychophysiological discrimination (FPD), consists of four items (4, 6, 13 and 20). Factor V, 
Table I Means and Standard Deviations in the HSPS-S Items in the EFA and CFA

\begin{tabular}{|c|c|c|c|c|c|}
\hline & \multirow[t]{2}{*}{ Items* } & \multicolumn{2}{|c|}{$\begin{array}{l}\text { EFA } \\
\text { Subsample } \\
\text { I }(n= \\
4091)\end{array}$} & \multicolumn{2}{|c|}{$\begin{array}{l}\text { CFA } \\
\text { Subsample } \\
2(n= \\
4170)\end{array}$} \\
\hline & & M & SD & M & SD \\
\hline 1 & Do you easily get overwhelmed by strong sensory stimuli? & 5.75 & 1.34 & 5.77 & 1.30 \\
\hline 2 & Do you seem to be aware of the subtleties around you? & 5.95 & 1.21 & 5.99 & 1.18 \\
\hline 3 & Do other people's moods affect you? & 6.18 & 1.16 & 6.20 & 1.10 \\
\hline 4 & Do you tend to be more sensitive to pain? & 5.05 & 1.66 & 5.06 & 1.70 \\
\hline 5 & $\begin{array}{l}\text { Do you need to get away and have some privacy during busy and hard work days in a dark room or in any } \\
\text { place where you can have some privacy and relief from so much stimulation? }\end{array}$ & 5.88 & 1.53 & 5.89 & 1.47 \\
\hline 6 & Are you particularly sensitive to the effects of caffeine? & 4.77 & 1.90 & 4.78 & 1.89 \\
\hline 7 & Do you easily feel overwhelmed by things like bright lights, strong smells, coarse fabric or nearby sirens? & 5.52 & 1.60 & 5.54 & 1.58 \\
\hline 8 & Do you have a rich and complex inner life? & 5.89 & 1.39 & 5.93 & 1.36 \\
\hline 9 & Do loud noises bother you? & 6.06. & 1.33 & 6.06 & 1.32 \\
\hline 10 & Are you deeply touched by the visual arts or music? & 6.14 & 1.21 & 6.19 & 1.18 \\
\hline II & $\begin{array}{l}\text { Does your nervous system sometimes make you feel so exhausted that you just want to get away from it } \\
\text { all? }\end{array}$ & 6.06 & 1.36 & 6.11 & 1.30 \\
\hline 12 & Are you conscientious? & 5.93 & 1.16 & 5.95 & 1.14 \\
\hline 13 & Do you get easily startled? & 5.31 & 1.64 & 5.27 & 1.63 \\
\hline 14 & Are you badly affected by having a lot to do in a short time? & 5.78 & 1.48 & 5.76 & 1.47 \\
\hline 15 & $\begin{array}{l}\text { When people feel uncomfortable in a physical environment, do you tend to know what needs to be done to } \\
\text { make them feel more comfortable (such as changing the lighting or seats)? }\end{array}$ & 5.39 & 1.43 & 5.40 & 1.40 \\
\hline 16 & Does it bother you when people make you do too many things at once? & 5.99 & 1.30 & 5.99 & 1.30 \\
\hline 17 & Do you try hard to avoid making mistakes or forgetting things? & 6.22 & 1.16 & 6.23 & 1.13 \\
\hline 18 & Do you try to avoid violent movies and television shows? & 5.14 & 1.94 & 5.17 & 1.91 \\
\hline 19 & Are you uncomfortable when a lot is going on around you? & 5.63 & 1,38 & 5.57 . & 1.39 \\
\hline 20 & Does being very hungry create a strong reaction in you, disrupting your concentration or mood? & 5.40 & 1.67 & 5.41 & 1.66 \\
\hline 21 & Do changes in your life affect you a lot? & 5.87 & 1.31 & 5.82 & 1.31 \\
\hline 22 & Do you easily notice delicate or fine aromas, flavors, sounds, works of art ... and enjoy them? & 5.98 & 1.28 & 5.99 & 1.27 \\
\hline 23 & Do you find it unpleasant when many things are happening at once? & 5.49 & 1.38 & 5.44 & 1.38 \\
\hline 24 & Do you give high priority to organizing your life to avoid disturbing or overwhelming situations? & 5.59 & 1.46 & 5.63 & 1.44 \\
\hline 25 & Are you disturbed by intense stimuli, such as loud noises or chaotic scenes? & 5.95 & 1.35 & 5.95 & 1.34 \\
\hline 26 & $\begin{array}{l}\text { When you compete or are watched while doing a task, do you get so nervous or shaky that you do it much } \\
\text { worse than you would? }\end{array}$ & 5.92 & 1.44 & 5.91 & 1.43 \\
\hline 27 & When you were a child, did parents or teachers seem to see you sensitive or shy? & 5.69 & 1.66 & 5.68 & 1.68 \\
\hline
\end{tabular}

Notes: *HSPS-S items reproduced from Aron and Aron.$^{2}$ Copyright $\odot$ 1997, American Psychological Association. 
Table 2 Comparison of Fit of the HSPS-S Models

\begin{tabular}{|l|l|l|l|l|l|l|}
\hline Factorial Solution & $X^{\mathbf{2}}$ & df & CFI & NNFI & RMSEA (90\% CI) & $\Delta$ CFI \\
\hline One-factor model & $11,051.63$ & 324 & 0.94 & 0.94 & $0.091(0.089-0.092)$ & 0.00 \\
\hline Three-factor model & 3506.71 & 101 & 0.96 & 0.95 & $0.090(0.087-0.093)$ & 0.00 \\
\hline Four-factor model & 4354.16 & 164 & 0.96 & 0.96 & $0.078(0.076-0.080)$ & 0.00 \\
\hline Five-factor first-order model & 4696.02 & 314 & 0.98 & 0.97 & $0.059(0.058-0.060)$ & 0.00 \\
\hline
\end{tabular}

Note: $p<0.001$.

Abbreviations: $X^{2}$, chi-square; $\mathrm{CFI}$, comparative fit index; NNFI, non-normed fit index; RMSEA, root mean square error of approximation; $\Delta C F I$, difference in CFI between models; $\mathrm{Cl}$, confidence interval.

called the harm avoidance (HA) dimension, is comprised of three items (12, 17 and 24) related to controlled harm avoidance (see Table 3). Explained variance of Factors II to $\mathrm{V}$ is $6.99 \%$ (Factor II), $5.10 \%$ (Factor III), 4.05\% (Factor IV) and 3.88\% (Factor V). Correlations between factors, after PROMAX rotation, ranged from 0.36 to 0.58 , and all factors together were statistically significant $(p<0.01)$.

\section{Confirmatory Factor Analysis of the HSPS-S}

A CFA was done with Subsample $2(n=4170)$ to test the suitability of the EFA structure. The five-factor model was selected because it had the best fit and the items made theoretical sense. The goodness-of-fit indices were CFI $=0.98$, NNFI $=0.97$, and RMSEA $=0.059(90 \% \mathrm{CI})$ (see Table 3 and Figure 1).

\section{Mean Gender Differences}

The comparison of means with Subsample 2 revealed significant differences between the five factors and total HSPS-S $(p<0.01)$. Women had significantly higher means and less dispersion in all factors and higher total scores than men on the SOS, AES and HA factors with small effect sizes, and medium on the total HSPS-S and LST and FPD factors (see Table 4).

The subgroup of highly sensitive people was determined by previously grouping the sample in terciles corresponding to low ( $\mathrm{P} \leq 33$ ), medium $(\mathrm{P} \geq 34$ and $\mathrm{P} \leq 66$ ) and high sensitivity. High sensitivity was considered equal to or above the 67 th percentile based on the total HSPS-S, which was surpassed by $32.83 \%$ of the participants. Following this criterion, the cut-off score for men was a total HSPS-S score of $\geq 160$ and for women $\geq 167$.

\section{Measurement Invariance}

A set of increasingly constrained models was used to evaluate invariance across sex (male vs female). The general idea is to compare the model fit when individual model parameters were estimated separately for different subpopulations with the fit when some parameters are fixed, they are constrained to be equal across subpopulations. $^{36}$ The invariance was proven with the following models from least to most constrained: ${ }^{37}$ Model 1, configural (the same factor structure in all groups); Model 2, metric (same factor load in all groups); and Model 3, scalar (same intercept in all items). In this context, when invariance is proven, in addition to demonstrating satisfactory fit of the model (DFI and NNFI), the increase in the CFI is also taken into account, considering it acceptable at $\leq 0.01$.

The goodness-of-fit indices of the models used were satisfactory and the increase in CFI was below 0.01 in the models tested, as shown in Table 5, so the translation of the HSPS adapted to the Spanish population may be said to be equivalent for men and women.

\section{Reliability of the HSPS-S}

Reliabilities for the final model were calculated using Subsample 2. The Cronbach's $\alpha$ and McDonald's $\omega$ for the subscales, respectively, were as follows: $\mathrm{SOS}=$ 0.86 and $0.87, \mathrm{AES}=0.79$ and $0.80, \mathrm{LST}=0.82$ and $0.85, \mathrm{FPD}=0.56$ and $0.57, \mathrm{HA}=0.67$ and 0.68 . For the total HSPS-S Score, they were $=0.92$ and 0.93. All scales can be considered internally consistent when the number of items is taken into account. Mean values and standard deviations for the subscales and total HSPS-S for the five-factor model were as follows: SOS: $M=52.17, S D=8.63$; AES: $M=35.73, S D=$ 5.19; LST: $M=28.48, S D=5.75$; FPD: $M=20.51, S D$ $=4.54$; HA: $M=17.82, S D=2.88$ and for total HSPS$\mathrm{S}: M=154.71, S D=21.68$. The correlations ranged from 0.10 to 0.61 , and therefore, with all items together, statistically significant $(\mathrm{p}<0.01)$. 
Table 3 Matrix of Factor Loadings Exploratory Factor Analysis (Principal Components Extraction/PROMAX Rotation)

\begin{tabular}{|c|c|c|c|c|c|c|}
\hline & \multirow[t]{2}{*}{ Items* } & \multicolumn{5}{|c|}{ Component Loadings } \\
\hline & & sos & AES & LST & FPD & HA \\
\hline 14 & Are you badly affected by having a lot to do in a short time? & 0.735 & & & & \\
\hline 16 & Does it bother you when people make you do too many things at once? & 0.713 & & & & \\
\hline 26 & $\begin{array}{l}\text { When you compete or are watched while doing a task, do you get so nervous or shaky that you } \\
\text { do it much worse than you would? }\end{array}$ & 0.598 & & & & \\
\hline 23 & Do you find it unpleasant when many things are happening at once? & 0.584 & & & & \\
\hline 11 & $\begin{array}{l}\text { Does your nervous system sometimes make you feel so exhausted that you just want to get away } \\
\text { from it all? }\end{array}$ & 0.569 & & & & \\
\hline 19 & Are you uncomfortable when a lot is going on around you? & 0.524 & & & & \\
\hline 21 & Do changes in your life affect you a lot? & 0.521 & & & & \\
\hline 5 & $\begin{array}{l}\text { Do you need to get away and have some privacy during busy and hard work days in a dark room } \\
\text { or in any place where you can have some privacy and relief from so much stimulation? }\end{array}$ & 0.519 & & & & \\
\hline 27 & When you were a child, did parents or teachers seem to see you sensitive or shy? & 0.409 & & & & \\
\hline 10 & Are you deeply touched by the visual arts or music? & & 0.688 & & & \\
\hline 22 & Do you easily notice delicate or fine aromas, flavors, sounds, works of art ... and enjoy them? & & 0.655 & & & \\
\hline 2 & Do you seem to be aware of the subtleties around you? & & 0.655 & & & \\
\hline 8 & Do you have a rich and complex inner life? & & 0.599 & & & \\
\hline 15 & $\begin{array}{l}\text { When people feel uncomfortable in a physical environment, do you tend to know what needs to } \\
\text { be done to make them feel more comfortable (such as changing the lighting or seats)? }\end{array}$ & & 0.557 & & & \\
\hline 3 & Do other people's moods affect you? & & 0.486 & & & \\
\hline 25 & Are you disturbed by intense stimuli, such as loud noises or chaotic scenes? & & & 0.761 & & \\
\hline 9 & Do loud noises bother you? & & & 0.750 & & \\
\hline 7 & $\begin{array}{l}\text { Do you easily feel overwhelmed by things like bright lights, strong smells, coarse fabric or nearby } \\
\text { sirens? }\end{array}$ & & & 0.708 & & \\
\hline I & Do you easily get overwhelmed by strong sensory stimuli? & & & 0.614 & & \\
\hline 18 & Do you try to avoid violent movies and television shows? & & & 0.490 & & \\
\hline 4 & Do you tend to be more sensitive to pain? & & & & 0.673 & \\
\hline 13 & Do you get easily startled? & & & & 0.668 & \\
\hline 6 & Are you particularly sensitive to the effects of caffeine? & & & & 0.474 & \\
\hline 20 & Does being very hungry create a strong reaction in you, disrupting your concentration or mood? & & & & 0.438 & \\
\hline 24 & Do you give high priority to organizing your life to avoid disturbing or overwhelming situations? & & & & & 0.673 \\
\hline 17 & Do you try hard to avoid making mistakes or forgetting things? & & & & & 0.601 \\
\hline \multirow[t]{3}{*}{12} & Are you conscientious? & & & & & 0.557 \\
\hline & Factor Correlations & & & & & \\
\hline & Factor II & 0.55 & & & & \\
\hline
\end{tabular}

(Continued) 
Table 3 (Continued).

\begin{tabular}{|l|l|l|l|l|l|l|}
\hline \multirow{2}{*}{} & Items* & \multicolumn{3}{|c|}{ Component Loadings } \\
\cline { 3 - 7 } & & SOS & AES & LST & FPD & HA \\
\hline & Factor III & 0.61 & 0.58 & & & \\
\hline & Factor IV & 0.57 & 0.42 & 0.52 & & \\
\hline & Factor V & 0.54 & 0.56 & 0.50 & 0.36 & - \\
\hline
\end{tabular}

Notes: The bottom part of the table corresponds to the correlations between the factors (Factor I = SOS sensitivity to overstimulation; Factor II = AES aesthetic sensitivity; Factor III = LST low sensory threshold; Factor IV = FPD fine psychophysiological discrimination; Factor V = HA harm avoidance). All correlations were statistically significant $(p<0.01)$. *HSPS-S items reproduced from Aron and, Aron. ${ }^{2}$ Copyright $@$ (997, American Psychological Association.

\section{Discussion}

This study provides an appropriate tool for SPS, validated in the Spanish population with good psychometrics, and coinciding with the original version, ${ }^{2}$ as well as with later adaptations in other countries with adult general populations. ${ }^{19-24}$ We contribute an adaptation with the highest level of linguistic, cultural and conceptual equivalence, without modifying any of the items on the scale, as demonstrated by correct interpretation of the 27 items adapted to Spanish.

The sample used for the Spanish adaptation was considerably larger than for most of the adult high sensitivity scales. The mean age was older, and it contained a mixed representation of workers in different sectors and participants from all the regions of Spain, therefore offering a more enriching perspective in the study of high sensitivity, more so considering that a third of the sample was in the highly sensitive person range according to the selected criteria. Our study showed women to be more affected in both the total HSPS-S and its factors in line with previous studies that have reported higher sensitivity of women. ${ }^{16}$

Our findings on the factorial structure of the Spanish version of the HSPS, were in agreement with previous studies, supporting the multidimensionality of the HSPS$\mathrm{S}$ and including essential facets of the trait in SPS theory, ${ }^{4}$ as reflected in most of the studies referenced, which had two and three-factor solutions. However, our study, with a five-factor structure, approaches the one found by Sengül-Inal and Sümer, ${ }^{24}$ an adaptation which discriminates inhibited behavior, the fourth essential facet of the SPS trait ${ }^{4}$ related to harm avoidance, in a fourth factor. Aron and Aron $^{2}$ considered the behavioral inhibition system as the neuropsychological substrate of the personality trait, and by Smolewska et $\mathrm{al}^{21}$ considered it an overall construct associated with SPS, as well as with its components. In the study by Sengül-Inal and Sümer, ${ }^{24}$ excessive sensitivity to negative stimuli, ease of excitation of the sensory system tends to be considered an indicator of response to stressful situations or events, demonstrating the relationship between sensitivity to overstimulation (SOS) and harm avoidance (HA).

Unlike previous general population studies, we found a fifth factor, fine psychophysiological discrimination (FPD). In previous studies, the four items that comprise it $\left(4,6,13\right.$ and 29) had saturated on the EOE factor, ${ }^{19-21}$ on the factor called processed sensitivity (PS), ${ }^{20}$ were modified, ${ }^{22}$ or left out altogether. ${ }^{23} \mathrm{We}$ at least partly share with Montoya-Pérez et $\mathrm{al}^{20}$ the concept that these items respond to processed sensitivity, understanding that sensitivity is the response or psychophysiological reaction an individual experiences when the stimulus has been interpreted, not just perceived. Thus, there would be a cognitive response, with attentional biases in people with anxiety trait. There is a tendency to focus attention automatically on potentially threatening external and internal stimuli, with a shorter response latency than those who do not have this trait, and this in turn causes them to remain anxious. This dimension of the HSPS-S would identify sensitivity to stress related to a special vulnerability or higher biological sensitivity to the context, ${ }^{38}$ and this reactivity could emerge disproportionately in highly stressful or protected environments. The study by Pérez-Chacón et $\mathrm{al}^{39}$ demonstrated that certain SPS characteristics would be risk factors for burnout and fatigue from compassion in healthcare and education professionals. Some studies have also demonstrated the relationship between pain, anxiety and SPS. ${ }^{40}$ In line with the above, hypersensitivity would lead to stronger attention to painful stimuli and stronger emotional reactions to pain. In most people, exposure to threatening stimuli contributes to habituation, diminishing anxiety. On the contrary, pain causes the opposite effect, 

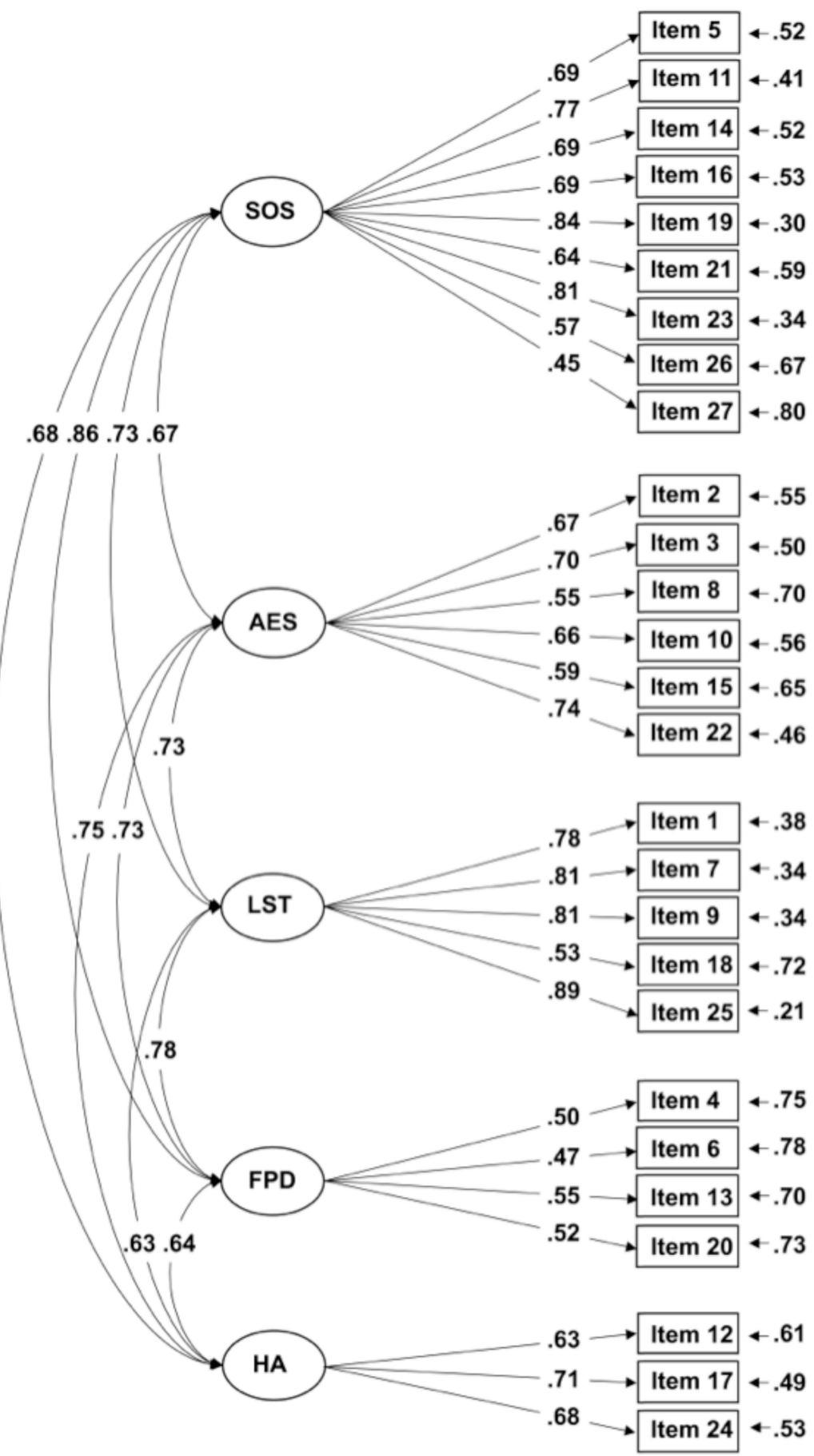

Figure I Model resulting from confirmatory factor analysis of HSPS-S.

higher sensitivity as a consequence of a reduction in prefrontal cortex modulation. ${ }^{41}$ This leads to greater anxiety, in some highly sensitive people, since in addition to exhaustively analyzing the threatening stimulus, they process this information more thoroughly. ${ }^{42}$ In the light of the results of our study, this more sensitive reaction made us wonder to what extent high sensitivity, in addition to having an innate component, would be affected by context or environment. That is, even though these people share a similar pattern as mentioned by Aron et al, ${ }^{4}$ the extent of their sensitivity to what occurs around them could differentiate them. 
Table 4 Mean Gender Differences

\begin{tabular}{|l|l|l|l|l|l|l|l|l|l|}
\hline & \multicolumn{3}{l}{ Male } & \multicolumn{2}{l|}{ Female } & & & & \\
\hline & $\mathbf{M}$ & SD & $\mathbf{M}$ & SD & $\boldsymbol{t}$ & $\mathbf{d f}$ & $\boldsymbol{P}$ & Cohen d & $\mathbf{9 5 \%} \mathbf{C l}$ \\
\hline Global HSPS-S & 148.23 & 24.83 & 155.73 & 21.99 & -7.170 & 855.440 & 0.000 & 0.34 & -9.550 to -5.440 \\
SOS & 50.95 & 9.58 & 52.57 & 8.74 & -3.998 & 868.680 & 0.000 & 0.18 & -2.440 to -0.824 \\
AES & 34.45 & 6.02 & 35.74 & 5.28 & -5.104 & 851.443 & 0.000 & 0.24 & -1.789 to -0.795 \\
LST & 26.22 & 6.54 & 28.83 & 5.50 & -9.541 & 841.650 & 0.000 & 0.46 & -3.156 to -2.079 \\
FPD & 19.29 & 4.92 & 20.72 & 4.40 & -7.021 & 859.266 & 0.000 & 0.32 & -1.864 to -1.049 \\
HA & 17.32 & 3.12 & 17.83 & 2.92 & -3.874 & 881.358 & 0.000 & 0.17 & -0.772 to -0.253 \\
\hline
\end{tabular}

Notes: male $\mathrm{n}=667$; female $\mathrm{n}=350$.

Abbreviations: SOS, sensitivity to overstimulation; AES, aesthetic sensitivity; LST, low sensory threshold; FPD, fine psychological discrimination; HA, harm avoidance; M, mean; SD, standard deviation; $t$, Student's $t$; $d$, Cohen's value (effect size); $\mathrm{Cl}$, confidence interval.

Table 5 Goodness-of-Fit Statistics for Tests of Measurement Invariance of the HSPS-S Across Sex

\begin{tabular}{|l|l|l|l|l|l|l|}
\hline Sex & $X^{\mathbf{2}}$ & df & CFI & NNFI & RMSEA (90\% CI) & $\Delta$ CFI \\
\hline Configural invariance & 5068.40 & 628 & 0.97 & 0.97 & $0.059(0.58-0.061)$ & 0.00 \\
Metric invariance & 5294.25 & 655 & 0.97 & 0.97 & $0.059(0.58-0.061)$ & 0.00 \\
Scalar invariance & 5371.10 & 668 & 0.97 & 0.97 & $0.059(0.58-0.061)$ & 0.00 \\
\hline
\end{tabular}

Note: $p<0.001$.

Abbreviations: $X^{2}$, chi-square; $\mathrm{CFI}$, comparative fit index; NNFI, non-normed fit index; RMSEA, root mean square error of approximation; $\Delta \mathrm{CFI}$, difference in CFI between models; $\mathrm{Cl}$, confidence interval.

Thus, a subscale that can identify hypersensitivity to both pain and the rest of psychophysiological and emotional responses of highly sensitive people in the HSPS-S, which has been shown to be equivalent for men and women, would be useful in establishing the relationship between high sensitivity and psychological affectations and complaints typical of central sensitivity syndrome, such as fibromyalgia, headache ${ }^{43}$ or chronic fatigue. ${ }^{44}$ It is also essential for future studies to be able to determine whether high sensitivity and central sensitivity have a parallel course, or on the contrary, high sensitivity would be a risk factor for developing central sensitivity syndrome. $^{45}$

This question is of special importance for designing and preparing intervention and prevention programs for highly sensitive people with presence of anxiety symptoms, emotional alterations and stress, and sensitization to pain. Cognitive-behavioral treatments have been demonstrating their efficacy in multicomponent interventions for the treatment of chronic affectations involving pain, ${ }^{46,47}$ for improving quality of life. ${ }^{40}$ There are very few controlled psychological studies on highly sensitive people, ${ }^{48}$ although it is true that people who demand professional help to manage their anxiety and depression tend to be diagnosed with a dysthymic disorder, and are treated with SSRI antidepressants and anxiolytics, and psychological intervention is for stress management and emotional alterations.

\section{Conclusions}

The results of the HSPS version validated for the Spanish population enable us to state that the HSPS-S has adequate psychometric properties comparable to other international studies. It maintains the 27 items that make up the original version integrating five high sensitivity components. It is considered suitable for use in daily clinical practice, for mental health conditions, stress and quality of life, especially for common mental disorders or problems, as well as for the professional who studies personalities with sensory processing sensitivity under different circumstances. In addition, it can be used in the workplace for detecting highly sensitive people and studying in greater depth the possible obstacles these people could have in performing their jobs and in their relations with the rest of the staff.

\section{Study Limitations}

We should mention as a limitation of this study that the sample was acquired through social networks closest to the researchers. However, we do not have any proof of bias in the sample properties, considered representative of the 
Spanish population. In addition, having employed convenience sampling, its application in a sample of exclusively highly sensitive people would remain pending, although a third of our study sample, a sufficiently representative percentage to be considered a limitation, responded to this pattern. Another limitation has to do with the possible bias in interpreting the items due to the use of self-report questionnaires. Similarly, the impossibility of checking criterion validity, there being no other high sensitivity scale validated for the Spanish population, implies that its results could only be compared with the original HSPS questionnaire, which was the gold standard. It should also be emphasized that, as no instruments were included for criterion and convergent validity, it would need to be determined what aspects of sensitivity are related to other constructs such as the classic version of neuroticism or negative affect. It remains for later studies to disentangle the sense of high sensitivity and its relationship with intolerance to stress and/or indicators of central sensitivity, affectation of the immune response, low threshold of pain, sleeping problems, or any other type of health dysfunction and alteration.

\section{Acknowledgments}

In the first place, we would like to thank the authors of the original scale, Arthur and Elaine Aron, for their support throughout the process. Secondly, thank the members of the Expert Committee for their time and effort. Our appreciation is made extensive to the Dean of the Faculty of Philology at Universidad Nacional de Educación a Distancia (UNED), the faculty members at several different universities for their involvement, and to the professionals who collaborated in the translation and linguistic and cultural adaptation of the scale and its distribution on the social networks. We also thank the Spanish Association of High Sensitivity Professionals and Psychologists (www.pasespana.org). Finally, our special thanks to the study participants for the interest demonstrated and for devoting their time to filling in the scale. This study for use in Spanish-speaking countries was made possible by all of their contributions.

\section{Disclosure}

The authors report no conflicts of interest in this work.

\section{References}

1. Pluess M. Individual differences in environmental sensitivity. Child Dev Perspect. 2015;9(3):138-143. doi:10.1111/cdep.12120
2. Aron EN, Aron A. Sensory-processing sensitivity and its relation to introversion and emotionality. J Pers Soc Psychol. 1997;73 (2):345-368. doi:10.1037/0022-3514.73.2.345

3. Aron EN, Aron A, Davies KM. Adult shyness: the interaction of temperamental sensitivity and an adverse childhood environment. Pers Soc Psychol Bull. 2005;31:181-197. doi:10.1177/ 0146167204271419

4. Aron EN, Aron A, Jagiellowicz J. Sensory processing sensitivity: a review in the light of the evolution of biological responsivity. Personal Soc Psychol Rev. 2012;16:262-282. doi:10.1177/ 1088868311434213

5. Bakker K, Moulding R. Sensory-processing sensitivity, dispositional mindfulness and negative psychological symptoms. Pers Individ Dif. 2012;53:341-346. doi:10.1016/j.paid.2012.04.006

6. Blach C, Egger JW. "Hochsensible Persönlichkeit"-Bericht zum Forschungsprojektzur Hochsensibilität. Psychologische Medizin. 2011;2:59-63.

7. Booth C, Standage H, Fox E. Sensory-processing sensitivity moderates the association between childhood experiences and adult life satisfaction. Pers Individ Dif. 2015;87:24-29. doi:10.1016/j. paid.2015.07.020

8. Liss M, Mailloux J, Erchull MJ. The relationships between sensory processing sensitivity, alexithymia, autism, depression, and anxiety. Pers Individ Dif. 2008;45:255-259. doi:10.1016/j. paid.2008.04.009

9. Evers A, Rasche J, Schabracq MJ. High sensory-processing sensitivity at work. Int J Stress Manag. 2008;15(2):189-198. doi:10.1037/ 1072-5245.15.2.189

10. Tillman T, Matany KD, Duttweiler H. Measuring environmental sensitivity in educational contexts: a validation study with German-speaking students. J Educ Dev Psychol. 2018;8(2):17-28. doi:10.5539/jedp.v8n2p17

11. Liss M, Timmel L, Baxley K, et al. Sensory processing sensitivity and its relation to parental bonding, anxiety, and depression. Pers Individ Dif. 2005;39(8):1429-1439. doi:10.1016/j.paid.2005.05.007

12. Ellis BJ, Boyce WT, Belsky J, et al. Differential susceptibility to the environment: an evolutionary-neurodevelopmental theory. Dev Psychopathol. 2011;23(1):7-28. doi:10.1017/s0954579410000611

13. Benham G. The highly sensitive person: stress and physical symptom reports. Pers Individ Dif. 2006;40(7):1433-1440. doi:10.1016/j. paid.2005.11.021

14. Redfearn RA, Van Ittersum KW, Stenmark CK. The impact of sensory processing sensitivity on stress and burnout in nurses. Int J Stress Manag. 2020;27(4):370-379. doi:10.1037/str0000158

15. Slagt M, Dubas JS, Van Aken MA, et al. Sensory processing sensitivity as a marker of differential susceptibility to parenting. Dev Psychol. 2018;54(3):543-558. doi:10.1037/dev00004

16. Dixon EA, Benham G, Sturgeon JA, et al. Development of the Sensory Hypersensitivity Scale (SHS): a self-report tool for assessing sensitivity to sensory stimuli. J Behav Med. 2016;39:537-550. doi:10.1007/s10865-016-9720-3

17. Ohla K, Lundström JN. Sex differences in chemosensation: sensory or emotional? Front Hum Neurosci. 2013;7:607. doi:10.3389/ fnhum.2013.00607

18. Hofmann SG, Bitran S. Sensory-processing sensitivity in social anxiety disorder: relationship to harm avoidance and diagnostic subtypes. $J$ Anxiety Disord. 2007;21(7):944-954. doi:10.1016/j. janxdis.2006.12.003

19. Ershova R, Yarmotz E, Koryagina T, et al. A psychometric evaluation of the highly sensitive person scale: the components of sensory-processing sensitivity. Electron J Gen Med. 2018;15(6):96. doi:10.1016/j.janxdis.2006.12.003

20. Montoya-Pérez KS, Ortega JIM, Montes-Delgado R, et al. Psychometric properties of the highly sensitive person scale in Mexican population. Psychol Res Behav Manag. 2019;12:1081-1086. doi:10.2147/prbm.s224808 
21. Smolewska K, McCabe S, Woody E. A psychometric evaluation of the highly sensitive person scale: the components of sensoryprocessing sensitivity and their relation to the BIS/BAS and "Big Five". Pers Individ Dif. 2006;40(6):1269-1279. doi:10.1016/j. paid.2005.09.022

22. Konrad S, Herzberg PY. Psychometric properties and validation of a German high sensitive person scale (HSPS-G). Eur J Psychol Assess. 2017;35(3):364-378. doi:10.1027/1015-5759/a000411

23. Grimen H, Diseth Å. Sensory processing sensitivity. Percept Mot Skills. 2016;123(3):637-653. doi:10.1177/0031512516666114

24. Şengül-inal G, Sümer N. Exploring the multidimensional structure of sensory processing sensitivity in Turkish samples. Curr Psychol. 2017;39:1-13. doi:10.1007/s12144-017-9751-0

25. Beaton DE, Bombardier C, Guillemin F, et al. Guidelines for the process of cross-cultural adaptation of self-report measures. Spine. 2000;25(24):3186-3191. doi:10.1097/00007632-200012150-00014

26. Wild D, Grove A, Martin M, et al. Principles of good practice for the translation and cultural adaptation process for Patient-Reported Outcomes (PRO) measures: report of the ISPOR Task Force for translation and cultural adaptation. Value Health. 2005;8(2):94-104. doi:10.1111/J.1524-4733.2005.04054.X

27. Muñiz J, Elosua P, Hambleton RK. Directrices para la traducción y adaptación de los tests: segunda edición. Psicothema. 2013;25 (2):151-157. doi:10.7334/psicothema2013.24

28. Pastor JM, Del Río C. Investigación Con Participantes Humanos. En C Del Rio y JM Pastor Ética Profesional En Salud Mental. Madrid Ediciones Pirámide; 2018:169-187.

29. Kaiser H. A second generation Little Jiffy. Psychometrika. 1970;35 (4):401-415. doi:10.1007/BF02291817

30. Bartlett MS. Tests of significance in factor analysis. $\mathrm{Br} J$ Psychol. 1950;3:77-85. doi:10.1111/j.2044-8317.1950.tb00285.x

31. Bentler PM. Comparative fit indexes in structural models. Psychol Bull. 1990;107(2):238-246. doi:10.1037/0033-2909.107.2.238

32. Hooper D, Coughlan J, Mullen M. Structural equation modelling: guidelines for determining model fit. EJBRM. 2008;6:53-60.

33. Cheung GW, Rensvold RB. Evaluating goodness-of-fit indexes for testing measurement invariance. Struct Equat Model. 2002;9 (2):233-255. doi:10.1207/S15328007SEM0902_5

34. Cohen J. Statistical power analysis. Curr Dir Psychol Sci. 1992;1 (3):98-101. doi:10.1111/1467-8721.ep10768783

35. Curran PJ, West S, Finch JF. The robustness of test statistics to nonnormality and specification error in confirmatory factor analysis. Psychol Methods. 1996;1(1):16-29. doi:10.1037/1082-989X.1.1.16

36. Byrne BM. Testing for multigroup equivalence of a measuring instrument: a walk through the process. Psicothema. 2008;20(4):872-882.

37. Vandenberg RJ, Lance CE, Review A. Synthesis of the measurement invariance literature: suggestions, practices, and recommendations for organizational research. Organ Res Method. 2000;3(1):4-70. doi: $10.1177 / 109442810031002$
38. Boyce WT, Ellis BJ. Biological sensitivity to context: an evolutionary-developmental theory of the origins and functions of stress reactivity. Dev Psychopathol. 2005;17(2):271-301.

39. Pérez-Chacón M, Chacón A, Borda-Mas M, Avargues-Navarro ML. Sensory processing sensitivity and compassion satisfaction as risk/ protective factors from burnout and compassion fatigue in healthcare and education professionals. Int $J$ Environ Res Public Health. 2021;18(2):611. doi:10.3390/ijerph18020611

40. Stern BZ, Strober LB, Goverover Y. Relationship between sensory processing patterns, trait anxiety, and health-related quality of life in multiple sclerosis. J Health Psychol. 2020;Epub. doi:10.1177/ 1359105319901316

41. Flor H, Diers M, Birbaumer N. Peripheral and electrocortical responses to painful and non-painful stimulation in chronic pain patients, tension headache and healthy controls. Neurosci Lett. 2004;361:147-150. doi:10.1016/j.neulet.2003.12.064

42. Beck AT, Clark DA. An information processing model of anxiety: automatic and strategic processes. Behav Res Ther. 1997;35:49-58. doi:10.1016/s0005-7967(96)00069-1

43. Wolf CJ. Central sensitization: implications for the diagnosis and treatment pain. Pain. 2011;152(3):52-515. doi:10.1016/j. pain.2010.09.030

44. Nijs J, Meeus M, Van Oosterwijck J, et al. In the mind or in the brain? Scientific evidence for central sensitisation in chronic fatigue syndrome. Eur J Clin Invest. 2012;42:203-212. doi:10.1111/j.13652362.2011.02575.x

45. Clark JR, Nijs J, Yeowell G, et al. Trait sensitivity, anxiety, and personality. Are predictive of central sensitization symptoms in patients with chronic low back pain? Pain Pract. 2019;19 (8):800-810. doi:10.1111/papr.12809

46. Cano-García FJ, González-Ortega MD, Sanduvete-Chaves S, Chacón-Moscoso S, Moreno-Borrego R. Evaluation of a psychological intervention for patients with chronic pain in primary care. Front Psychol. 2017;8:435. doi:10.3389/fpsyg.2017.00435

47. Lazaridou A, Kim J, Cahalan CM, et al. Effects of Cognitive-Behavioral Therapy (CBT) on brain connectivity supporting catastrophizing in fibromyalgia. Clin $J$ Pain. 2017;33 (3):215-221. doi:10.1097/AJP.0000000000000422

48. Greven CU, Lionetti F, Booth $\mathrm{CH}$, et al. Sensory processing sensitivity in the context of environmental sensitivity: a critical review and development of research agenda. Neurosci Biobehav Rev. 2019;98:287-305. doi:10.1016/j.neubiorev.2019.01.009
Psychology Research and Behavior Management

\section{Publish your work in this journal}

Psychology Research and Behavior Management is an international, peer-reviewed, open access journal focusing on the science of psychology and its application in behavior management to develop improved outcomes in the clinical, educational, sports and business arenas. Specific topics covered in the journal include: Neuroscience, memory and decision making; Behavior modification and management; Clinical applications; Business and sports performance management; Social and developmental studies; Animal studies. The manuscript management system is completely online and includes a very quick and fair peer-review system, which is all easy to use. Visit http://www dovepress.com/testimonials.php to read real quotes from published authors. 